\title{
A LEWY-STAMPACCHIA INEQUALITY IN VARIABLE SOBOLEV SPACES FOR PSEUDOMONOTONE OPERATORS
}

\author{
A. Mokrane And G. VAllet
}

Abstract. In this paper, we are interested in proving the Lewy-Stampacchia inequality in the general framework of an obstacle problem for a nonlinear pseudomonotone elliptic operator in $W_{0}^{1, p(\cdot)}(\Omega)$ where $p(\cdot)$ is a log-Hölder continuous exponent. Our aim is to adapt to the context of variable exponent Sobolev spaces a previous work of the first author, based on a penalization method.

Mathematics subject classification (2010): 35J85, 35R35.

Keywords and phrases: Lewy-Stampacchia inequality, pseudomonotone operator, variable exponent spaces.

\section{REFERENCES}

[1] S. Antontsev, S. Shmarev, Anisotropic parabolic equations with variable nonlinearity, Publ. Mat., 53, (2) (2009), 355-399.

[2] A. Azevedo, J. F. Rodrigues, L. Santos, The $N$-membranes problem for quasilinear degenerate systems, Interfaces Free Bound, 7, (3) (2005), 319-337.

[3] V. BARBU, Nonlinear differential equations of monotone types in Banach spaces, Springer Monographs in Mathematics. Springer, New York (2010).

[4] L. BocCARDo, Lewy-Stampacchia inequality in quasilinear unilateral problems and application to the G-convergence, Boll. Unione Mat. Ital. (9), 4, (2) (2011), 275-282.

[5] S. Challal, A. Lyaghfouri, J. F. Rodrigues, On the A-obstacle problem and the Hausdorff measure of its free boundary, Annali di Matematica, 191 (2012), 113-165.

[6] L. Diening, P. HaRJulehto, P. Hästö, M. RUZicka, Lebesgue and Sobolev Spaces with Variable Exponents, Springer (2011).

[7] X. FAN, D. ZHAO, On the spaces $L^{p(x)}(\Omega)$ and $W^{m, p(x)}(\Omega)$, J. Math. Anal. Appl., 263, (2) (2001), 424-446.

[8] J. Giacomoni, G. Vallet, Some results about an anisotropic p $(x)$-Laplace-Barenblatt equation, Advances in Nonlinear Analysis, 1, (3) (2012), 277-298.

[9] O. KovÁčí, J. RÁкоsník, On spaces $L^{p(x)}$ and $W^{k, p(x)}$, Czechoslovak Math. J., 41, (4) (1991), 592-618.

[10] C. LeOne, On a class of nonlinear obstacle problems with measure data, Comm. Partial Differential Equations, 25, (11-12) (2000), 2259-2286.

[11] H. LEWY, G. STAMPACCHIA, On the smoothness of superharmonics which solve a minimum problem, J. Analyse Math., 23 (1970), 227-236.

[12] M. Matzeu, R. ServadeI, Semilinear elliptic variational inequalities with dependence on the gradient via mountain pass techniques, Nonlinear Anal., 72, (11) (2010), 4347-4359.

[13] A. Mokrane, F. Murat, A proof of the Lewy-Stampacchia's inequality by a penalization method, Potential Anal., 9, (2) (1998), 105-142.

[14] A. Mokrane, F. Murat, Proving the Lewy-Stampacchia inequality by penalization, Atti Semin. Mat. Fis. Univ. Modena, 46(Suppl.) (1998), 315-334.

[15] A. Mokrane And F. Murat, Sur l'inégalité de Lewy-Stampacchia pour le problème bilatéral et pour le problème quadratique, Matematiche, 60, (2) (2005), 299-314. 
[16] A. Mokrane, F. Murat, The Lewy-Stampacchia inequality for bilateral problems, Ric. Mat., 53, (1) (2004), 139-182.

[17] F. Murat, A. Mokrane, The Lewy-Stampacchia inequality for the obstacle problem with quadratic growth in the gradient, Ann. Mat. Pura Appl., IV. Ser., 184, (3) (2005), 347-360.

[18] S. OUARO, S. TRAORE, Entropy solutions to the obstacle problem for nonlinear elliptic problems with variable exponent and $L^{1}$-data, Pac. J. Optim., 5, (1) (2009), 127-141.

[19] M.-C. PALMERI, Homographic approximation for some nonlinear parabolic unilateral problems, J. Convex Anal., 7, (2) (2000), 353-373.

[20] J.-F. RodRIGUES, Obstacle problems in mathematical physics, volume 134 of North-Holland Mathematics Studies, Notas de Matemática [Mathematical Notes], 114, Amsterdam (1987).

[21] J.-F. RodRIGUES, Stability remarks to the obstacle problem for p-Laplacian type equations, Calc. Var. Partial Differential Equations, 23, (1) (2005), 51-65.

[22] J.-F. RODRIGUES, M. SANCHÓN, J.-M. URBANO, The obstacle problem for nonlinear elliptic equations with variable growth and $L^{1}$-data, Monatsh. Math., 154, (4) (2008), 303-322.

[23] J.-F. Rodrigues, R. Teymurazyan, On the two obstacles problem in Orlicz-Sobolev spaces and applications, Complex Var. Elliptic Equ., 56, (7-9) (2011), 769-787.

[24] R. Servadei, E. VAldinoci, Lewy-Stampacchia type estimates for variational inequalities driven by (non)local operators, Rev. Mat. Iberoam., 29, (3) (2013), 1091-1126.

[25] G. M. Troianiello, Elliptic differential equations and obstacle problems. The University Series in Mathematics. Plenum Press, New York (1987). 